

Volume 9, General Issue (2021)

\title{
Why Won't They Just Adopt Good Research Data Management Practices? An Exploration of Research Teams and Librarians' Role in Facilitating RDM Adoption
}

Clara Llebot \& Hannah Gascho Rempel

Llebot, C. \& Rempel, H.G. (2021). Why Won't They Just Adopt Good Research Data Management Practices? An Exploration of Research Teams and Librarians' Role in Facilitating RDM Adoption. Journal of Librarianship and Scholarly Communication, 9(General Issue), eP2321.

https://doi.org/10.7710/2162-3309.2321 


\title{
Why Won't They Just Adopt Good Research Data Management Practices? An Exploration of Research Teams and Librarians' Role in Facilitating RDM Adoption
}

\author{
Clara Llebot \\ Data Management Specialist, Oregon State University \\ Hannah Gascho Rempel \\ Science Librarian, Oregon State University
}

Adoption of good research data management practices is increasingly important for research teams. Despite the work the research community has done to define best data management practices, these practices are still difficult to adopt for many research teams. Universities all around the world have been offering Research Data Services to help their research groups, and libraries are usually an important part of these services. A better understanding of the pressures and factors that affect research teams may help librarians serve these groups more effectively. The social interactions between the members of a research team are a key element that influences the likelihood of a research group successfully adopting best practices in data management. In this article we adapt the Unified Theory of the Acceptance and Use of Technology (UTAUT) model (Venkatesh, Morris, Davis, \& Davis, 2003) to explain the variables that can influence whether new and better, data management practices will be adopted by a research group. We describe six moderating variables: size of the team, disciplinary culture, group culture and leadership, team heterogeneity, funder, and dataset decisions. We also develop three research group personas as a way of navigating the UTAUT model, and as a tool Research Data Services practitioners can use to target interactions between librarians and research groups to make them more effective. 


\section{IMPLICATIONS FOR PRACTICE}

1. Programmatic implications: the adapted UTAUT model described in this article can help librarians offering research data services to characterize the research teams they want to target, to identify the teams they are currently reaching, as well as those research groups that are underserved.

2. Implications relative to the effectiveness of librarians interacting with a research team: becoming more familiar with the variables that influence research group behavior and teams' subsequent willingness or ability to incorporate new behaviors can improve librarians' effectiveness.

3. Implications relative to the tools available to librarians: in this article we propose several tools that may help librarians characterize research teams. We propose the use of personas to design research data services; we inventory the research data services offered and what kind of groups they tend to reach; and we provide a template worksheet to help librarians widen the reach of existing research data services.

\section{INTRODUCTION}

For several decades, the research community has been engaged in a debate about the need to make research more reproducible (Baker, 2016), the virtues and dangers of open science and open data (Nosek et al., 2015; Tenopir et al., 2011), and devising better ways to manage data (Perkel, 2019). From this debate the importance of adopting research data management $(\mathrm{RDM})$ best practices has become increasingly apparent. RDM best practices have emerged such as the FAIR (Findable, Accessible, Interoperable, Reusable) guiding principles (Wilkinson et al., 2016), which were developed to enhance the reusability of published datasets, not only from the point of view of the researchers wanting to reuse data, but also from a computational point of view so machines can find and use data automatically without relying on human interpretation. Even though most RDM principles, such as the FAIR data principles, are discipline agnostic, different fields of research are at very different points in their journey to define what RDM best practices are and how to adopt them.

Policy changes among research funders around the world have also stressed the need for data management. For example, in the United States a memorandum from the Office of Science and Technology Policy in 2013 (Holdren, 2013) urged federal funders to make results of federally funded research publicly available. Since the publication of that memo, the requirements for quality data management in the U.S., including writing data management plans and requirements to share data, have become increasingly demanding and specific, both by federal agencies and other funders. For example, in 2019 the National Science 
Foundation issued a Dear Colleague Letter (National Science Foundation, 2019) encouraging the use of persistent identifiers for data, and machine-readable data management plans. In Europe the Open Research Data Pilot, part of the European Union Horizon 2020 program, requires participating projects to submit data management plans to be updated over the course of the project and to share data at the end of the project (Directorate-General for Research \& Innovation, 2016). In 2018 Canada published a Tri-Agency Research Data Management draft policy for consultation (Government of Canada, 2018) and planned to approve it in 2020 (postponed due to the COVID-19 pandemic). The policy, when approved, will apply to grant recipients and institutions administering tri-agency funds, and will require institutions to create a research data management strategy, encourage researchers to write data management plans with grant proposals, and require grant recipients to deposit data into repositories.

Because RDM is a skill researchers need, many institutions offer Research Data Services (RDS). In particular, requirements to write data management plans and requirements to make data publicly accessible have driven the creation of RDS in research institutions. Development of RDS often involves several stakeholders, such as the research office, information services, and the library. Despite significant efforts on the part of librarians, researchers, and funding agencies, RDM best practices are still difficult to implement. In this article we will focus on the implementation of RDS from the point of view of the library.

Libraries have created services that range from consultation to hands-on data curation services, creation of educational guides for researchers, workshops and classes on data management, and maintenance of data repositories (Cox, Kennan, Lyon \& Pinfield, 2017). To inform the development of RDS, libraries often perform environmental scans in which they assess the needs and challenges faced by researchers in their institutions and the resources already available to them (see a few examples, among many others in Reznik-Zellen, Adamick, \& McGinty, 2012; Goldman, Kafel, \& Martin, 2015; Whitmire, Boock, \& Sutton, 2015). There are also frameworks that facilitate the development and improvement of RDS in higher education institutions (Rans \& White, 2017). Several studies have also addressed the challenges faced by researchers when trying to adopt best data management practices, particularly regarding data sharing (Tenopir, Dalton, Allard, Grame \& Pjesivac, 2015; Stuart et al, 2018).

However, a key element in the adoption of new research tools or data management processes that has not been previously addressed is the social interaction between members of a research team. Collaborative work is increasingly expected in research settings as teams tackle transdisciplinary problems and attempt to increase their overall scholarly impact (Wuchty, Jones, \& Uzzi, 2007). Establishing a process for data sharing is one example where the need 
for communication and collaboration among research team members becomes evident, as the adoption of data sharing workflows presents challenges and opportunities based on a variety of team characteristics.

As Cooper and Springer (2019) note when promoting the idea of data communities, data sharing is fundamentally social. Understanding how research teams collaborate and adopt new workflows or processes can give librarians working with research groups an opportunity to better understand research teams at their own institutions, the issues they face, and how particular kinds of group dynamics have greater (or lesser) implications for adopting new practices like data sharing and management. We will discuss how data management issues in research teams vary based on a range of factors highlighted in the literature on management, organizational psychology, and technology adoption, and the social science of research, with a particular emphasis on exploring how theoretical models might be adapted to better conceptualize the choices and services librarians provide. This paper presents a theoretical model based on our experiences, expertise, and extensive review of the literature. The purpose of the article is to give librarians who work with research data management a structured way to reflect on their practices and spark new conversations about the influence of research team dynamics on RDM adoption and use.

\section{LITERATURE REVIEW}

\section{Team Approaches to Communication Problems}

Prior to reviewing the literature, we reflected on our experiences working with researchers, and we observed that the success of RDM implementation often hinges on research teams' ability to communicate with each other (and the librarian). In other words-there is a social component to RDM implementation. As a result, we delved into the literature on research team dynamics. Research teams vary based on factors at the macro level such as disciplinary culture, and at the individual level based on team member characteristics such as personality. We examined the literature for factors at the team level as well as the personal level to help better understand the dynamics impacting team-wide adoption of new practices. We also kept in mind factors that RDS librarians could use to navigate consultations with research teams. In particular we found characteristics related to team size, disciplinary culture, leadership and team culture, and team heterogeneity to be important influencers of team dynamics, and we will discuss literature related to these four characteristics.

\section{Team Size}

There are challenges as well as benefits to increased research team size. Kinzie et al. (2007) 
describe struggles they encountered in a research project with more than 20 collaborators who had different commitment levels, varying methodological approaches and ways of interpreting the data, and diverse writing styles. However, increased variety in a research team due to increased size can also be beneficial because more diverse ideas can arise, thereby resulting in the ability to solve more complex problems (Ductor, 2015; Liggett, Glesne, Johnston, Hasazi, \& Schattman, 1994). As teams increase in size, they also require more administrative oversight, which typically results in a higher level of organization across the team.

\section{Disciplinary Culture}

Disciplinary culture can have a significant impact on how teams work together. For example, social scientists working with qualitative data need to negotiate shared practices for evaluating data to achieve shared meaning making (Kinzie et al., 2007). Other examples of different disciplinary practices come from the natural sciences. When comparing synthetic chemists and physicists, Velden (2013) found that synthetic chemistry teams were more driven by individual skill and reputation, whereas the physics teams valued joint leadership and collective achievements, in part because physicists need to share highly expensive machinery. As a result, the physicists were more open in their communication approaches and more likely to share their works in progress with the broader physics community. Disciplinary culture can also influence how data sharing works across teams. For example, in a review of a sample of papers that received National Science Foundation award funding in environmental biology, a diverse field with many types of methodologies, authors were found to be more likely to share when genetics data was included in their study. As a result, the researchers noted, "a cultural shift has occurred in disciplines that produce genetic data, regardless of journal requirements, these data are shared, while other types of data are not" (Hampton et al., 2013, p. 158). In a survey with 1329 scientist participants representing a broad array of disciplines including physical, biological, and social sciences, Tenopir and collaborators (2011) found that when asked if others can "access my data easily" (p. 9) $23.5 \%$ of atmospheric scientists and $15.6 \%$ of biologists in their study agreed strongly that others could and should be able to access their data, whereas only $6.5 \%$ of medical researchers and $5.4 \%$ of social scientists agreed strongly.

Disciplinary culture also influences attitudes toward what sociology of science researchers refer to as openness or secrecy. Cultural approaches related to openness and secrecy may be less immediately obvious but can stem from implicit disciplinary values and practices. For example, in Velden's (2013) examination of chemists' research habits she found that because of a disciplinary culture that was highly concerned with getting their research results out first before getting "scooped," a tradition of what she described as secrecy had developed 
that resulted in reduced information sharing between researchers. In contrast, physicists more frequently brainstormed with other researchers and shared their emerging ideas because of a disciplinary culture that emphasized solving problems collaboratively. The degree to which a discipline uses human subjects' data also influences the views of researchers in the discipline regarding sharing, because these researchers are responsible for protecting the confidentiality of their research subjects. For example, in a study about perceptions of data sharing by scientists around the world Tenopir et al. (2015) found that researchers in fields that work with human subjects (medicine, health sciences, education, psychology) were less willing to share, and were more inclined to think that their data should not be available to others, and that in fact they did not have the right to make their data available. Most disciplinary cultures fall somewhere along the continuum of sharing and openness, as researchers navigate the balance between communicating their findings broadly and withholding some of their discoveries in order to receive adequate credit for their work (Evans, 2010).

\section{Group Culture \& Leadership}

While disciplinary culture or group composition can have enduring impacts on how teams behave, the personality and characteristics of individual members within a team also influences how teams work. Obviously, individual characteristics can have both positive and negative impacts on teams, but negative impacts are more commonly studied. In a systematic review of relationship and task conflict, De Dreu and Weingart (2003) found that both conflicts about specific tasks, including disagreements about resource distribution or policies and procedures, and relationship conflicts, including values, interpersonal style, and personal tastes, could be equally disruptive for team performance. Similarly, Healey, Vuori, and Hodgkinson (2015) found that when team members held similar ideas about the tasks they were responsible for, they were better able to work toward a consistent and productive outcome.

The contribution of each individual member of a team is important, but in research teams the principal investigator (PI) usually holds the most power and influence over the tasks the team undertakes, has the strongest connection to a particular disciplinary culture, and also creates the "personality" of the team (López-Yánez \& Altopiedi, 2015). Perhaps one of the PI's most important contributions is their ability to generate ideas. Idea generation is more likely when leaders have at least some level of multidisciplinary expertise, because this expertise often results in more innovative teams (Salazar \& Lant, 2018). Specifically, Salazar and Lant note that multidisciplinary experience is important because leaders with broader experience are more likely to be able to bring more people and different types of expertise into the conversation. Another important function PIs have is providing overall continuity to research teams as well as acting as a "knowledge bank" (Velden, 2013, p. 5). Students 
and post-doctoral fellows may come and go from a research team, but the PI historically participates in the same or similar research teams throughout their careers. Of course, PIs vary in their level of experience and the choices they make shift accordingly throughout their careers. For example, Piwowar (2011) found that data sharing was more likely when researchers were more experienced. Similarly, Tenopir and collaborators (2011) found that researchers over 50 were more interested in sharing their data.

PIs choose different ways to lead and establish their research team's group culture and ways of working together. These leadership choices can impact how efficiently a team works, how likely they are to adopt new practices, and the willingness to collaborate with other research teams. One way of describing leadership styles is as either autocratic or democratic. Autocratic leaders tend to provide strong central decision-making whereas democratic leaders tend to distribute decision-making responsibilities throughout their teams. Productive research teams can result from either leadership approach. After studying molecular life scientists, Hackett (2005) observed that both the most and the least successful teams resulted from strong central decision-making approaches. Similarly, De Hoogh and collaborators (2015) found that when there were few team power struggles, autocratic leadership led to positive team performance. But when there were many team power struggles, the autocratic approach negatively impacted team performance. When a PI takes on too many roles themselves, without building the capacity of others on the team, opportunities for productivity and discoveries can be diminished (Azoulay, Zivin, \& Wang, 2010).

\section{Team Heterogeneity}

As has already been suggested, teams made up of diverse or heterogeneous members can be more innovative and productive (Leahey, 2016). But heterogeneity can be defined in many ways, and as noted earlier in the exploration of team size, challenges can arise when a team is more diverse. One example of heterogeneity is when teams are made up of members from multiple countries. Not only are there cultural norms to navigate, but teams working at a distance from each other have to find ways to work together and solve problems - including conflict-based problems-virtually (Griffith, Mannix, \& Neale, 2003). Wilson and collaborators (2020) present another example of researcher heterogeneity. In their study teams were comprised of members from 13 academic institutions (including Historically Black Colleges \& Universities, Hispanic Serving Institutions, Tribal Colleges and Universities, and a land grant university), nine disciplinary areas (including social sciences, environmental sciences, physical and life sciences), as well as a variety of career stages from student to full professor. An intervention was introduced with the goal of increasing the teams' creativity levels. While the researchers found it was possible to increase creativity, they noted that sustained support structures were necessary to overcome group conflicts and to help bal- 
ance the tension between individual and group goals. Success may also need to be measured somewhat differently for more diverse teams, as when Choudhury and Haas (2018) discovered that diverse teams created more advantageous products (in their example the products were patents), but it took longer to complete their products.

\section{Models Explaining Group Behaviors}

All of the factors and characteristics of teams-size, disciplinary culture, leadership and group culture, and heterogeneity-impact a team's willingness and tendency toward adoption of new approaches. We sought models from a variety of disciplines, including organizational psychology, communications, and human-computer interaction, to help us better understand the barriers research teams might face as they tried to adopt data management practices. Models about group communication, such as the Conflict-Outcome Moderated Model (De Wit, Greer, \& Jehn, 2012), the Model of Knowledge Sharing, Structural Diversity, and Performance in Work Groups (Cummings, 2004), and the Group Behavior Model (Gladstein, 1984) provided fascinating insights into group behaviors, but did not provide us with a way to better describe the implications of how introducing a new set of tasks to a group might influence the group's willingness and ability to adopt those new behaviors. As a result, we turned to technology adoption models, especially those models that include a social component as part of the process of adopting new technology. We take a broad view of research technologies and used Hackett's definition, which defines research technologies as "the materials, techniques, instruments, theories, and ideas that research groups use" (2005, p. 788). An early model in this field is the Technology Acceptance Model (TAM) (Davis, 1989). TAM focuses on users' willingness to accept new technology based on the perceived usefulness of the tool and the ease of using the tool. What was lacking from this model for our needs was the influence of other people on the technology adoption process.

The Unified Theory of the Acceptance and Use of Technology (UTAUT) model (Venkatesh, Morris, Davis, \& Davis, 2003) extended TAM by including not only the perceived usefulness and ease of using a technology — what are referred to as "direct determinants" of eventual adoption and use - but also included social influence and the facilitating conditions provided by the larger environment, e.g., the institution, as direct determinants of behavioral change. The UTAUT model also introduced "moderating variables" that situationally impact the direct determinants of technology adoption and use. Not all moderating variables impact each direct determinant, and not all moderating variables impact each direct determinant to the same degree. The moderating variables proposed by Venkatesh and collaborators were gender, age, experience, and voluntariness of use. Each of these moderating variables described an individual's behavior, as the context within which Venkatesh's team was working was on how management could introduce new technologies to employees. 
Others have adapted the UTAUT model over time because of its ability to predict variance in behavioral intention and the flexibility of the direct determinants and the moderating variables on technology adoption and use (Im, Hong, \& Kang, 2011; Kim, Hebeler, Yoon, \& Davis, 2018; Zuiderwijk, Janssen, \& Dwivedi, 2015). Based on our review of the literature and our own experience working with researchers on data issues, we propose a variation of the UTAUT model for exploring the adoption and use of data management practices that includes the following moderating variables based on research culture: size, disciplinary culture, leadership and group culture, funder expectations, heterogeneity, and dataset-dependent decisions. We have not altered the original model's direct determinants of performance, effort, social influence, and facilitating conditions, as we believe these fundamental (and most influential) aspects of determining behavioral change remain the same across most contexts. We will be using this adapted model for the remainder of the paper. A visualization of the adapted UTAUT model is shown in Figure 1.



Figure 1. UTAUT model (Venkatesh et al., 2003) adapted to explain the adoption of RDM best practices in research teams. The direct determinants are displayed on the left side of the model. The moderating variables are displayed on the top of the model. The moderating variables descend in their level of proposed decision-making use by RDM librarians interacting with research teams from left to right.

\section{Exploring RDM Adoption with the UTAUT Model}

To illustrate how the UTAUT model can inform RDS work, we began by reflecting on our 
own research practices and work with researchers. Our work was informed by the experiences we have had in different roles. We have both been graduate students and have been part of research teams in our respective former fields of horticulture and oceanography, and we have participated in research activities throughout the research life cycle. We hold positions in an academic library and interact with graduate students, faculty, and research teams on a regular basis. Our interactions with these researchers often focus on managing information, and frequently are specifically devoted to managing research data. We also engage in library research as part of our position description, and we have worked on research projects in which we collected interviews with members of research teams, and had conversations with them about data management (for example Rempel \& Robertshaw, 2017). Our application of a theoretical lens to RDM adoption practices has not been developed by collecting a dataset or direct testing, but instead has been informed by a literature review, our experience as members of a research team, our professional practice, and structured information collected as part of research projects in the library field. In the following section we use this combination of experiences to discuss realistic (but theoretical) scenarios we developed in which to conceptualize our adaptation of the UTAUT model in the context of RDS.

\section{Research Team Personas}

One approach for developing realistic scenarios in which to explore theories is the use of personas. Personas are a technique that was originally introduced as a design tool to help developers, who may not always be experts in usability concepts, design computer applications that are easy to use (A. Cooper, 2004). Personas are not real people, but imaginary archetypical people who have precise characteristics, goals, and needs. Personas are developed by the team during the investigative process of the product being designed, and the product is developed with these hypothetical people in mind. Personas can be used in other fields, and they have been used in library research (see, for example, Rempel \& Markland (2018) describing social experiences of graduate students, analyzed through personas, and how librarians can use this information to increase engagement with graduate students).

In this article we use personas to define archetypical research teams. Defining hypothetical research groups is helpful at two levels. First, it was a methodological step, useful to interrogate our adaptations of the UTAUT model. Defining the research team personas and exploring the moderating variables that influence the adoption of research data management by these teams was an iterative process. Second, personas can be used to evaluate how effectively a library's research data services are designed to interact with different types of groups. The personas we developed incorporated moderating variables from our adaptation of the UTAUT model. To avoid creating an overwhelming number of research team personas exhibiting variations of the six moderating variables, we chose two key variables based on our 
review of the literature and lived experiences, which facilitate understanding of the social impacts of RDM adoption: "team size," and "leadership and group culture."

The moderating variable "team size" was not chosen because it is the most important characteristic of research teams - indeed disciplinary culture can often be very impactful—but in terms of ease of use from the point of view of a librarian initiating RDS with new research teams. It will be much easier for a librarian, especially a librarian who is not specialized in a particular discipline, to characterize a research group based on size, rather than on characteristics like leadership style and group culture, or disciplinary culture, and then propose relevant services accordingly.

First, we defined three personas based on different team sizes: Small, Medium, and Large research groups. For the purposes of this discussion, we defined Small research groups as containing 2-8 members, Medium research groups as containing 9-40 members, and Large research groups as containing more than 40 members. (These group sizes are drawn from descriptions of research groups in the literature, for example, Hoffman et al., 2014; Kinzie et al., 2007, as well as our own experiences and interactions with research groups.) Next, we incorporated variations of the other moderating variables in a way that reflects situations that are both most and least favorable for adoption of good data management practices including disciplinary culture and funder requirements for RDM. The personas were given personalities primarily driven by their principal investigator's (PIs) characteristics such as level of experience and management style due to the large influence the PI has on how a research team functions. However, our intention was that the focus would remain on the group, not just the PI. The following is a description of the three research team personas.

Small research team: Sunita Bose directs a small university-based research lab working on organic berry production. Her research group consists of one full-time research technician, and she typically has two to three graduate students. In the summer she often has an undergraduate student researcher working on a short-term project, as well as two to three seasonal workers to assist with crop maintenance tasks and data collection. The research fields are located at a nearby university-owned experiment station. Sunita is an associate professor and has been at this university for 10 years. Her research projects include a few long-term studies examining yield, fruit quality, and plant health indicators. She frequently collaborates with USDA researchers in the region. Recently, they have begun looking at the intersection of human health and the consumption of organic small fruits. Data are collected using a variety of types of equipment, but most frequently data collection results in CSV data files that are imported into Excel and R. Variations of this small group persona can be found at Llebot and Rempel (2020) [https://ir.library.oregonstate.edu/concern/parent/5x21tn73z/ file sets/2v23w206z]. 
Medium research team: Melissa Gonzalez is a public health researcher at a large research university who focuses on demography. She is overseeing an NIH-funded project exploring suicide prevention strategies for LGBTQ adolescents. This project includes on-campus partners from the Colleges of Education, Nursing, Public Health, and the School of Psychology, as well as two partners from other universities. Melissa currently advises three graduate students who are working on various components of this research project in pursuit of their dissertations. She is co-advising these students with a frequent collaborator from the College of Education. Her College of Education partner has a network of high school administrator contacts throughout the state. These administrators are providing access to students from their target population with whom they are conducting multi-year interviews and focus groups. In order to explore a wide range of prevention strategies, Melissa is also collaborating with colleagues at her own institution in nursing and counseling. For the design and analysis of the study, Melissa reached out to experts at other universities in the region to help craft the qualitative portion of the study. Melissa oversaw the design of the quantitative portion of the study. While Melissa is the lead PI, there are a total of six investigators on this grant from a total of three universities. With the three graduate students and the 10 high school administrators involved in regular data collection, the overall size of the research team is 19 people. Variations of this medium group persona can be found at Llebot and Rempel (2020) [https://ir.library.oregonstate.edu/concern/parent/5x21tn73z/file sets/ k3569b69p].

Large research team: David $\mathrm{Li}$ is the principal investigator for a bioinformatics research project that studies mutations of the human genome that can be linked to forms of breast cancer. Most of the data collected is genomics data, but the research team also works with medical information from breast cancer patients, and with environmental data. The research project is a long-term collaboration among 10 universities in the United States, France, and China. Each of the subprojects involves 1-5 investigators, several graduate students and postdocs, and 1 or 2 technicians. The total size of the project team includes over 150 researchers. The funds for the project come mainly from federal agencies from the three countries. In addition, smaller amounts have been donated by private, non-profit institutions. Contracts with industry are minor, because this is mostly basic research, but some of the subprojects have collaborations with industry groups. David and the administrative team, as well as David's own research group, are located in a medical university in California, and hold frequent meetings with all of the teams via online meeting software. Once a week, the principal investigators of all the projects at the 10 universities meet to talk about their teams' progress, and once a year they meet in person at one of the universities participating in the project. The PIs make decisions in their meetings that are enforced in their teams. It is important that the results of different teams are comparable, so the PIs pay close attention to methodology, protocols, instrumentation, and data management. Several 
of the subprojects have full-time data managers on their teams who are in charge of supporting data management challenges, maintaining the servers where the data is stored, and submitting the data into centralized databases, which the whole team has access to. Many of the RDM decisions were made at the beginning of the project, including the identification of data and metadata standards, an agreement for how the data would be shared among the members of different teams, details on how they would protect human research datasets generated during the project, a schedule for data publishing, and a procedure for training new members of the team on data management practices. Variations of this large persona can be found at Llebot and Rempel (2020) [https://ir.library.oregonstate.edu/concern/parent/5x21tn73z/file sets/3n204581i].

\section{APPLICATION OF PERSONAS TO THE UTAUT MODEL}

To demonstrate how the UTAUT model can help conceptualize RDM adoption practices, we will discuss how each moderating variable, illustrated by the scenarios of the three personas, affects the most relevant direct determinants' contribution to the adoption of RDM practices (see Table 1). A brief contextual note-while the scenarios represented by the personas help visualize archetypical research teams, they of course do not accurately represent all research teams and are not generalizable. Descriptions of each persona was provided to help build a shared discussion around the likelihood of adopting new research technologies based on social structures of research teams. To help create a shared conversation about adoption of new research technologies or practices, we will discuss the specific RDM practice of making data publicly available in a way that facilitates reuse. This best practice includes thorough documentation, placement of data in an open repository with a permanent identifier, and the choice of a license clarifying how the data may be reused (Goodman et al., 2014).

\section{Team Size}

Small size teams can negatively affect the direct determinant performance expectancy, because based on the team resources available it may seem that putting too much effort into preparing datasets for publication is not worth the effort. With a small team it can be easier to communicate with the members of the team when questions arise, and then to send datasets to the occasional researcher who asks for them after reading a published article. Of course, depending on the team, different behaviors may be observed. Some small teams may struggle to communicate because of lack of role clarity. In contrast, for large teams sharing datasets can have clear advantages. Many of these advantages, such as avoiding the need to answer repeated requests for data, creating opportunities for new collaborations with other researchers interested in similar data, and promoting the research outputs of the team, are also beneficial 


\begin{tabular}{|c|c|c|c|}
\hline \multicolumn{4}{|c|}{ Moderating Variable } \\
\hline \multirow[t]{2}{*}{ Direct Determinant } & Size & & \\
\hline & Small & Medium & Large \\
\hline Performance & - & + & + \\
\hline Effort & + & - & - \\
\hline Social Influence & - & + & + \\
\hline \multirow[t]{3}{*}{ Facilitating Conditions } & - & + & + \\
\hline & \multicolumn{3}{|c|}{ Disciplinary Culture } \\
\hline & \multicolumn{2}{|c|}{ Secret, No Data Standards } & Open, Uses Data Standards \\
\hline Performance & \multicolumn{2}{|c|}{-} & + \\
\hline Effort & \multicolumn{2}{|c|}{-} & + \\
\hline Social Influence & \multicolumn{2}{|c|}{-} & + \\
\hline \multirow[t]{3}{*}{ Facilitating Conditions } & \multicolumn{2}{|c|}{-} & + \\
\hline & \multicolumn{3}{|c|}{ Group Culture \& Leadership } \\
\hline & \multicolumn{2}{|c|}{$\begin{array}{c}\text { Democratic, Inexperienced } \\
\text { Leader, Clashing Personalities }\end{array}$} & $\begin{array}{c}\text { Autocratic, Experienced Leader, } \\
\text { Collaborative Personalities }\end{array}$ \\
\hline Performance & \multicolumn{2}{|c|}{-} & + \\
\hline Effort & \multicolumn{2}{|c|}{-} & + \\
\hline Social Influence & \multicolumn{2}{|c|}{1} & + \\
\hline \multirow[t]{3}{*}{ Facilitating Conditions } & & & + \\
\hline & \multicolumn{3}{|c|}{ Funder } \\
\hline & \multicolumn{2}{|c|}{ No Requirements } & Requirements \\
\hline Performance & \multicolumn{2}{|c|}{ NA } & NA \\
\hline Effort & \multicolumn{2}{|c|}{+} & - \\
\hline Social Influence & \multicolumn{2}{|c|}{ NA } & NA \\
\hline Facilitating Conditions & \multicolumn{2}{|c|}{-} & + \\
\hline
\end{tabular}

Table 1. Theoretical continuum of the effect of the moderating variables on the direct determinants of best practice data sharing behaviors. The minus symbol indicates the direct determinant leading to the behavior is more difficult; the plus symbol indicates the behavior is easier to facilitate based on the moderating variable; the slash symbol indicates that the behavior could go either way and is more highly influenced by other moderating variables. (Table continues on following page) 
Team Heterogeneity

\begin{tabular}{lcc}
\hline & Heterogeneous & Homogenous \\
\hline Performance & $/$ & $/$ \\
\hline Effort & - & + \\
\hline Social Influence & $/$ & $/$ \\
\hline Facilitating Conditions & - & + \\
\hline & Dataset Decisions & Large, non-sensitive, quan- \\
\hline & Small, sensitive, qualitative & titative \\
\hline Performance & & + \\
\hline Effort & - & / \\
\hline Social Influence & - & NA \\
\hline Facilitating Conditions & NA & + \\
\hline
\end{tabular}

Table 1. (continued)

for small teams. But larger teams may accrue larger benefits from the administrative streamlining that can come with creating systems for data sharing. For the direct determinant effort expectancy, small teams can have an advantage. To make changes in their workflow, they only need to train and convince a few researchers. If Sunita decided to start sharing data openly, she would just need to convince her full-time research technician and make slight changes to how she trains her new students. If David or Melissa decide to share data, they would need to make sure all researchers on their team are on board, not just about the concept of sharing data, but also about all the details of documenting data for publication, repositories to use, etc. In general, effort expectancy may be negatively affected in medium and large groups, and can be positively affected for small teams.

One way to interpret the direct determinant of social influence in the case of research teams could mean the influence of local colleagues (we will account for the influence of the disciplinary culture as a separate moderating variable). Small teams have few members, and in some cases, like Sunita's, there are many students and early career researchers. Therefore, there may be relatively fewer opportunities to encounter the importance of data sharing through departmental activities like attending seminars, departmental meetings and emails, and conversations in the corridor. A large team may make up a significant proportion of the researchers in a particular college, and as in the case of David's group, may include multiple institutions and countries. As a result, the social influence may be larger in teams with more members. 
In a similar way, it may be harder for small teams to be aware of the direct determinant of facilitating conditions in the form of supports such as data management librarians and institutional repositories that accept datasets for deposit. In a medium or large group, information about these resources may be more likely to be known because at least some of the researchers will likely encounter them and inform their colleagues. Consequently, small group size may tend to negatively affect facilitating conditions.

\section{Disciplinary Culture}

Disciplinary culture affects all four direct determinants on the continuum of impact similarly (see Table 5). Some disciplines have open cultures in which standards are well established and used by most of the members of the group. For example, David's group works on bioinformatics. Even though it is a relatively new field, there is a history of researchers in this field agreeing on the value of sharing data (Knoppers et al., 2011), there are expectations about how and where data should be shared, and the conversation about RDM in the discipline is active. Sunita, on the other hand, works in a branch of agriculture in which many of the research products are patentable. Consequently, Sunita's field values secrecy (see earlier explanation of secrecy in the literature review, Velden, 2013) and has not actively developed standards or expectations around data sharing. A secretive discipline (as described by Velden) will tend to negatively influence all the direct determinants. Performance expectancy is likely to be negatively impacted because in a secretive discipline, researchers are less likely to perceive data sharing as bringing benefits to the research. Effort expectancy can be negatively influenced because without accepted standards it can take more time and work to figure out the details of where, when, how, and in which format to share data. Social influence may be similarly impacted because there will likely be more colleagues who belong to the same field, and within this insular culture there could be less perceived value in data sharing. Finally, facilitating conditions may be more difficult to realize because it can be harder to find sharing tools, software, repositories, and support for a discipline that never uses these tools than for a discipline that does.

\section{Group Culture \& Leadership}

Independent of the disciplinary culture, individual research groups have their own culture that can be highly affected by the personality of the PI. Melissa could be interested in open practices even though she works in a field in which the collection of highly sensitive data makes data sharing complicated. She could work with the IRB to identify as much data as possible to be shared, or identify ways of sharing data securely after screening researchers who express interest in the data. She could also design and document transparent, open research methods without compromising the confidentiality of her participants. A researcher 
like Melissa who had an autocratic leadership style would make sure these practices were adopted by all the members of her project, however reluctant the team members may be. An autocratic leader in this scenario would positively affect the performance expectancy, as the PI would create a detailed plan for data sharing in the project, and would communicate the expectations to other participants so the benefits of data sharing would be clearly understood. This type of autocratic strategy would also positively affect the effort expectancy, as having clear workflows and expectations would ease the work necessary to share data effectively. In an autocratic group where most decisions are made by the PI, social influence can play a role only if it affects the PI, because what the PI decides will affect the whole group. A scenario with an inexperienced Melissa, who is not sure about the possible benefits of data sharing, in combination with a democratic management style where all individual researchers make their own decisions even if they are not in agreement, could be much less likely to result in sharing data-especially in an environment where there are concerns about maintaining the privacy of research subjects. Social influence will likely weakly affect a democratic group of researchers, because the influences may be different for each member of the team and will affect only that member of the team. Having a clear and unified strategy to make data publicly available within the group could be beneficial for identifying resources to facilitate the task. As a result, facilitating conditions could be positively affected.

\section{Gatekeepers-Funders and Publishers}

Requirements from funding agencies and publishers can have a strong influence on the decision to adopt data sharing behaviors, as founder and publisher requirements can directly affect ultimate behaviors without affecting the direct determinants. It is still unclear how much policy is affecting practice (Neylon, 2017), but in the 2019 State of Open Data Report, journal or publisher requirements were found to be the fourth highest motivator for data sharing and funder requirements was ranked sixth (Digital Science). Funders with highly specific requirements could negatively affect the effort expectancy because of the work required to adopt sharing behaviors. But they can positively affect facilitating conditions because it is likely that the funders and the institutions interested in getting funding will create infrastructure for support. Similarly, publishers are increasingly creating infrastructure to both require and support data depositing behaviors, and as a result, data sharing as an appendix to an article is now the most common form of data sharing (Digital Science, 2017). Facilitating condition types of infrastructure supports include a repository that accepts datasets, federal agencies that create or sponsor discipline-specific data repositories, academic societies that encourage data sharing, or academic libraries with data management librarian positions. 


\section{Team Heterogeneity}

A high level of team heterogeneity can have positive effects. For example, having a team with researchers from different disciplines may increase the likelihood of there being a researcher that advocates for good data management practices. High heterogeneity may also negatively affect the likelihood that a team will adopt data management practices. For example, David's team is very heterogeneous, because it includes members from several countries, members at different stages of their careers, and members working in different disciplines. The heterogeneity of the group is not likely to have a significant effect on the performance expectancy. However, a team like this may have a harder time figuring out a common strategy for sharing data. They may need to identify several repositories, perhaps in different countries, or work with standards and formats that are fundamentally different. Thus, team heterogeneity can negatively affect the effort expectancy, as a heterogeneous team may have to work harder to share their data than a homogeneous team. Social influence can be weaker in a group of people that have heterogeneous circumstances and points of view, and so it may be less likely to have an effect. The facilitating conditions can also be negatively affected, as the infrastructure for data sharing is likely also more distributed.

\section{Dataset Decisions}

Datasets can be easier or harder to share depending on the datasets' characteristics. The direct determinants can be affected in many different directions. Quantitative data that does not include information about human subjects, can be relatively straightforward to share. Datasets that need to be protected for some reason (e.g., human subjects or potential commercialization), pose more challenges. Our three personas illustrate examples of research groups that have some reason to protect their data: possible commercialization in the case of Sunita, and human subjects in the case of Melissa and David's data. Performance expectancy can be affected positively by non-sensitive datasets like David's, because it can be easier to see that sharing these datasets will have specific advantages, such as getting multiple perspectives on complex problems (National Academy of Sciences (U.S.), National Academy of Engineering (U.S.), and Institute of Medicine (U.S.) Committee on Ensuring the Utility and Integrity of Research Data in a Digital Age, 2009). Sharing sensitive datasets will likely require more effort, because it will be necessary to make sure research subjects will be protected. In particular, sharing human subjects research would need to be planned from the beginning of the research, as an explanation about the intent of sharing is usually required in consent forms. Sensitive data are harder to share, but researchers working on sensitive data are usually trained, are typically aware of the need for protecting research subjects, and are likely to have thought carefully about whether data can be shared and how. 


\section{DISCUSSION}

Research data services have grown past their infancy and are now an established part of many academic libraries' service offerings. To help critically and creatively re-examine the state of RDS, we have presented two approaches for thinking about adoption of RDM best practices within the social context of research teams. The UTAUT model has been presented in combination with personas as a way to illustrate how the moderating variable characteristics associated with many research teams play out in a realistic RDM situation. In the discussion section we will reflect on how the UTAUT model and the persona examples can help RDS programs strategize ways to work with different research teams.

\section{Limitations}

As we begin this discussion, which will emphasize implications for librarians based on the adapted UTAUT model, we would like to reflect on the limitations of this type of approach. First, this work is not intended to be generalizable. As with many qualitative approaches, our use of personas is meant to provide a deep description so readers can see how these personas do (or don't) match with their own knowledge of their constituents' behavior. Hopefully these personas will allow readers to identify similarities and differences between their own contexts, and then to construct mental models of researchers and research teams at their own institutions based on the examples we have provided. The second limitation is that the UTAUT model was created to help explain behaviors when employees within a corporate context are asked to adopt new technologies. We believe there is a clear argument for considering RDM best practices as analogous to adopting new technologies, and we also believe that people in research settings are similarly influenced by the direct determinants of performance, effort, social influence, and facilitating conditions identified in the UTAUT model. But we also recognize there are differences between corporate culture and academic culture. Our hope is that the moderating variables we identified have helped to assuage those differences, but there may still be some gaps between these two cultures that we have not clearly identified.

We primarily focused on research team behaviors related to data sharing in the United States because we are most familiar with the regulations and policy expectations in that context. But we recognize that data management requirements tend to be funder and country specific, and there are countries and funders with no data management requirements. Therefore, the establishment of RDS programs and the services provided by these programs varies widely by country.

Each of these limitations gets at the tension involved in translating theory into practice. 
The use of theories can help us be more strategic and systematic as we create and evaluate our practices. Theories are typically based on a broad range of experiences and are then tested to determine if they consistently illustrate their intended principles. But they are only useful in practice if combined with reflection and a critical examination of the local context.

\section{IMPLICATIONS FOR LIBRARIANS}

\section{Librarians' Current Approach to Research Data Services}

To frame our discussion of how these theories might influence RDS librarians' practices, we needed to establish a clear picture of the various ways libraries and librarians have defined and addressed data management needs. We began by inventorying the RDS services described in the literature. For this inventory we compiled information from studies that evaluate the services offered by RDS programs at the time of the study, as well as literature describing the potential of RDS in library settings, and pathways for successful development of these programs. Even though most libraries have been working on managing research data for a long time, the constitution of RDS as a specific set of services around data emerged in the early 2010s. Since then, much has been written and researched about this topic. Cox and collaborators (2017) surveyed libraries in Australia, Canada, Germany, Ireland, Netherlands, New Zealand, and the U.K. about the RDS established in their libraries and summarized data collected from studies in these same countries (Corrall, Kennan, \& Afzal, 2013; Cox \& Pinfield, 2014; Tenopir et al., 2015; Tenopir, Birch, \& Allard, 2012; Whyte, 2014). Their questionnaire included a list of 22 RDS services. Similarly, Tenopir, Sandusky, Allard, and Birch (2014) surveyed libraries in the U.S. and Canada, using a list of 12 services provided by RDS. Rans and White (2017) describe the development of research data services in higher education institutions, suggesting services that can be included in these services. Lewis (2010) describes nine areas libraries can work on to further data management best practices.

The services offered by libraries are commonly divided into informational and consulting RDS and technical hands-on RDS. The level of expertise needed to offer these two kinds of services is very different, the first one being more similar to traditional librarian services than the second one. As noted earlier, we decided to define our personas first based on team size, and then on leadership and group culture. The focus on team size is grounded in practicality rather than importance, as it is much easier for a librarian to quickly ascertain the size of a research group via an in-take form or an initial research consultation than to ask probing (and potentially loaded) questions about group culture and leadership style. Following this practicality principle, rather than organizing our inventory using the consulting 
and technical classifications, we classified the RDS services described in the literature according to the type of librarian-service interaction with the researchers (see Table 2). This classification provides a new way of identifying how librarians can assist teams of researchers in adopting data management practices. The librarian-service classifications are as follows:

Transversal services: Services that affect or have the potential to affect everybody in an institution, regardless of their role in a research project, the characteristics of the group, or the type of research. Transversal services transmit generalizable knowledge that has to be interpreted for each application. It takes a long time to create these services, but once they are created, it is relatively straightforward to apply them to specific cases.

Group services: Services that affect a group of people who concurrently have something in common. Services offered under this model can only be generalizable to specific types of knowledge that is relevant to the particular group. Librarians providing this type of service model need a medium range of time for application, as providing RDS at this level may require several hours of preparation and will likely require work from the data librarian in the form of repeat consultations after the interaction.

One-on-one services: Services that affect individuals in a research team, or that are manifested in conversations or interactions with only one or a few people. These services are usually highly specific, with an output that is tailored to a challenge a single individual is experiencing. These interactions are relatively short, lasting only a few minutes to a few hours and require limited preparation and follow up.

One way to begin adapting RDS based on the UTAUT model is for librarians to first identify which of the service examples identified in Table 2 are offered at their institution. Next, librarians can discern trends or gaps in their service, then they can use the moderating variables for research group behavior to identify what types of groups are currently using the services. The disciplinary culture and funder moderating variables have clear impacts on ultimate RDM adoption behaviors. Librarians should familiarize themselves with common RDM disciplinary practices and funder requirements. But in addition to these moderating variables, variables more closely tied to social behaviors should also be considered. A relatively easy, but impactful social moderating variable to use in this inventory is research group size. Research group size influences many of the other group social behaviors and is more socially acceptable to discuss during an intake consultation as compared to asking whether a PI uses democratic or autocratic leadership approaches (although those leadership approaches may be observed or discussed informally). As a result, categorizing the users (and non-users) of RDS by this characteristic provides opportunities for librarians to ask questions about why certain service groupings are used more or less frequently by certain size groups. Librarians 


\begin{tabular}{|c|c|c|c|}
\hline & Transversal services & Group services & One-on-one services \\
\hline $\begin{array}{l}\text { Time } \\
\text { required }\end{array}$ & $\begin{array}{l}\text { Takes a lot of time and } \\
\text { resources to set up the } \\
\text { service, but once created, } \\
\text { the application is relatively } \\
\text { fast. }\end{array}$ & $\begin{array}{l}\text { Medium range of time, from } \\
\text { several hours to weeks. }\end{array}$ & $\begin{array}{l}\text { Relatively short, from } \\
\text { a few minutes to a few } \\
\text { hours. }\end{array}$ \\
\hline $\begin{array}{l}\text { Type of } \\
\text { knowledge } \\
\text { transferred }\end{array}$ & $\begin{array}{l}\text { Generalizable knowledge } \\
\text { that has to be interpreted } \\
\text { for each application. }\end{array}$ & $\begin{array}{l}\text { Ranges from generalizable to } \\
\text { specific knowledge }\end{array}$ & $\begin{array}{l}\text { Very specific knowledge } \\
\text { tailored to a distinct chal- } \\
\text { lenge }\end{array}$ \\
\hline $\begin{array}{l}\text { Researchers } \\
\text { affected }\end{array}$ & $\begin{array}{l}\text { All researchers in an insti- } \\
\text { tution }\end{array}$ & $\begin{array}{l}\text { Group of researchers who have } \\
\text { something in common }\end{array}$ & $\begin{array}{l}\text { One person or a very small } \\
\text { group }\end{array}$ \\
\hline $\begin{array}{l}\text { Service } \\
\text { examples }\end{array}$ & $\begin{array}{l}\text { 1. Lead the development } \\
\text { of an institutional research } \\
\text { data management policy } \\
\text { 2. Influence data policies } \\
\text { external to the institution } \\
\text { (a) national (b) interna- } \\
\text { tional (c) funders } \\
\text { 3. Create and maintain } \\
\text { web-based guides with data } \\
\text { management advice } \\
\text { 4. Provide access to tools } \\
\text { that promote or enhance } \\
\text { robust data management } \\
\text { 5. Provide access to exter- } \\
\text { nal data sources } \\
\text { 6. Perform long-term pres- } \\
\text { ervation of research data } \\
\text { 7. Provide a data catalogue } \\
\text { to improve findability of the } \\
\text { institution's research data } \\
\text { 8. Run a data repository/ } \\
\text { archive/store } \\
\text { 9. Develop researcher data } \\
\text { awareness } \\
\text { 10. Outreach and promotion } \\
\text { of data sources. }\end{array}$ & $\begin{array}{l}\text { 1.Group consultations and advi- } \\
\text { sory services including (a) data } \\
\text { management planning (b) data } \\
\text { storage (c) data publication (d) } \\
\text { data analysis (e) data visualization } \\
\text { (f) data documentation (g) data } \\
\text { standards (h) copyright, licensing, } \\
\text { and intellectual property around } \\
\text { datasets (i) data curation of active } \\
\text { data (j) data preservation (k) data } \\
\text { citation } \\
\text { 2. Participation of librarians in } \\
\text { research projects as a member of } \\
\text { the team } \\
\text { 3. Training and instruction in } \\
\text { data literacy to undergraduate, } \\
\text { graduate students, staff, and } \\
\text { faculty. This training can take } \\
\text { several forms (a) short workshops } \\
\text { (b) credit classes (c) non- credit } \\
\text { classes (d) study groups } \\
\text { 5. Take on responsibility for } \\
\text { actively curating research data (a) } \\
\text { creating metadata (b) preparing a } \\
\text { dataset for deposit in a repository } \\
\text { (c) transferring formats } \\
\text { 6. Managing collections of } \\
\text { datasets, identifying datasets for } \\
\text { deposit and deselecting datasets. }\end{array}$ & $\begin{array}{l}\text { 1. Research data manage- } \\
\text { ment advisory service to } \\
\text { researchers } \\
\text { 2. Advisory services: most } \\
\text { of the advisory services } \\
\text { mentioned in the group } \\
\text { consultation and advisory } \\
\text { services can be done for an } \\
\text { individual or small group. } \\
\text { 3. Support researchers in } \\
\text { their efforts to research and } \\
\text { retrieve data from external } \\
\text { sources } \\
\text { 4. Take on responsibility } \\
\text { for curating active data } \\
\text { (a) creating metadata } \\
\text { (b) preparing dataset for } \\
\text { deposit in a repository (c) } \\
\text { transferring formats }\end{array}$ \\
\hline
\end{tabular}

Table 2. Research data services classified by the type of librarian-service interaction with researchers. 
can then use this identification of service patterns to set goals and target ways to add value to encourage research groups to use services in a more impactful category. For example, if a library identifies that they are currently only offering one-on-one services, they could set a goal to begin offering group services. Finally, RDS librarians could use this inventory to identify the library stakeholders needed to create and deliver services in new or different areas. For a worksheet approach to conducting this inventory, see Llebot and Rempel, 2020 [https:// ir.library.oregonstate.edu/concern/parent/5x21tn73z/file sets/pg15bn798].

While the moderating variable research group size describes and impacts many research group behaviors, librarians desiring a more nuanced approach to their analysis of the RDS they currently offer so as to shift to more impactful and targeted services could apply additional moderating variables to their inventory. For example, a consideration of the disciplines typically served, the research group communication styles most frequently observed, or the level of heterogeneity of the research groups served could help librarians develop outreach plans to underserved groups. Alternatively, librarians might decide to focus their RDS to better target and serve the types of research groups that most commonly use their services. Certain research group commonalities might emerge that may not have been immediately apparent, such as high research group heterogeneity. If some of these variables are not immediately apparent, a practice we suggest is to begin employing an intake form. This intake form could be administered either formally or informally to capture the research group moderating variables of the researchers and students served that are currently unknown. Both strategies can benefit from defining personas, similar to the personas modeled in this work, which are based on the reality of the local institution and the desired reach of RDS.

We believe becoming more familiar with the many variables that influence research group behavior and team's willingness or ability to incorporate new behaviors can improve librarians' effectiveness. In addition, identifying the characteristics of research groups that lead to more successful adoption of RDM best practices can help inform future programmatic decisions. Librarians impact several of the direct determinants in the UTAUT model, including effort, social influence, and facilitating conditions. Adopting strategies that maximize the impact of these direct determinants by considering research group moderating variables will aid libraries in facilitating increased RDM adoption

\section{REFERENCES}

Azoulay, P., Zivin, J. S. G., \& Wang, J. (2010). Superstar extinction. The Quarterly Journal of Economics, 125(2), 549-589. https://doi.org/10.1162/qjec.2010.125.2.549 
Baker, M. (2016). Is there a reproducibility crisis? Nature, 533(7604), 452-454. https://doi.org/10.1038 $\underline{1533452 \mathrm{a}}$

Choudhury, P., \& Haas, M. R. (2018). Scope versus speed: Team diversity, leader experience, and patenting outcomes for firms. Strategic Management Journal, 39(4), 977-1002. https://doi.org/10.1002/smj.2753

Cooper, A. (2004). The inmates are running the asylum. Sams. Indianapolis, IN.

Cooper, D., \& Springer, R. (2019). When enough isn't enough: Rethinking research support in the sciences. Association of College \& Research Libraries, 132-138. http://www.ala.org/acrl/sites/ala.org.acrl/files/content /conferences/confsandpreconfs/2019/WhenEnoughisntEnough.pdf

Corrall, S., Kennan, M. A., \& Afzal, W. (2013). Bibliometrics and research data management services: Emerging trends in library support for research. Library Trends, 61(3), 636-674. https://doi.org/10.1353 $\underline{\text { lib.2013.0005 }}$

Cox, A. M., Kennan, M. A., Lyon, L., \& Pinfield, S. (2017). Developments in research data management in academic libraries: Towards an understanding of research data service maturity. Journal of the Association for Information Science and Technology, 68(9), 2182-2200. https://doi.org/10.1002/asi.23781

Cox, A. M., \& Pinfield, S. (2014). Research data management and libraries: Current activities and future priorities. Journal of Librarianship and Information Science, 46(4), 299-316. https://doi.org/10.1177 $\underline{10961000613492542}$

Cummings, J. N. (2004). Work groups, structural diversity, and knowledge sharing in a global organization. Management Science, 50(3), 352-364. https://doi.org/10.1287/mnsc.1030.0134

Davis, F. D. (1989). Perceived usefulness, perceived ease of use, and user acceptance of information technology. MIS Quarterly, 13(3), 319-340. https://doi.org/10.2307/249008

De Dreu, C. K. W., \& Weingart, L. R. (2003). Task versus relationship conflict, team performance, and team member satisfaction: A meta-analysis. Journal of Applied Psychology, 88(4), 741-749. https://doi.org/10 $.1037 / 0021-9010.88 .4 .741$

De Hoogh, A. H. B., Greer, L. L., \& Den Hartog, D. N. (2015). Diabolical dictators or capable commanders? An investigation of the differential effects of autocratic leadership on team performance. The Leadership Quarterly, 26(5), 687-701. https://doi.org/10.1016/j.leaqua.2015.01.001

De Wit, F. R., Greer, L. L., \& Jehn, K. A. (2012). The paradox of intragroup conflict: A meta-analysis. Journal of Applied Psychology, 97(2), 360. https://doi.org/10.1037/a0024844

Digital Science, Fane, B., Ayris, P., Hahnel, M., Hrynaszkiewicz, I., Baynes, G., \& Farrell, E. (2019). The State of Open Data Report 2019. https://doi.org/10.6084/m9.figshare.9980783.v2

Digital Science, Hahnel, M., Treadway, J., Fane, B., Kiley, R., Peters, D., \& Baynes, G. (2017). The State of Open Data Report 2017. https://doi.org/10.6084/m9.figshare.5481187.v1 
Directorate-General for Research \& Innovation. (2016). H2020 programme guidelines on fair data management in Horizon 2020. European Commission. http://ec.europa.eu/research/participants/data/ref /h2020/grants manual/hi/oa pilot/h2020-hi-oa-data-mgt en.pdf

Ductor, L. (2015). Does co-authorship lead to higher academic productivity? Oxford Bulletin of Economics and Statistics, 77(3), 385-407. https://doi.org/10.1111/obes.12070

Evans, J. A. (2010). Industry collaboration, scientific sharing, and the dissemination of knowledge. Social Studies of Science, 40(5), 757-791. https://doi.org/10.1177/0306312710379931

Gladstein, D. L. (1984). Groups in context: A model of task group effectiveness. Administrative Science Quarterly, 29(4), 499-517. https://doi.org/10.2307/2392936

Goldman, J., Kafel, D., Martin, E., \& Martin, E. (2015). Assessment of data management services at New England region resource libraries. Journal of EScience Librarianship, 4(1). https://doi.org/10.7191 /jeslib.2015.1068

Goodman, A., Pepe, A., Blocker, A. W., Borgman, C. L., Cranmer, K., Crosas, M., Di Stefano, R., Gil, Y., Groth, P., Hedstrom, M., Hogg, D. W., Kashyap, V., Mahabal, A., Siemiginowska, A., \& Slavkovic, A. (2014). Ten simple rules for the care and feeding of scientific data. PLoS Computational Biology, 10(4), e1003542. https://doi.org/10.1371/journal.pcbi.1003542

Government of Canada (2018). DRAFT Tri-Agency Research Data Management Policy For Consultation. Innovation, Science and Economic Development Canada. Retrieved December 7, 2020, from http://www .science.gc.ca/eic/site/063.nsf/eng/h 97610.html

Griffith, T. L., Mannix, E. A., \& Neale, M. A. (2003). Conflict and virtual teams. In S. G. Cohen \& C. B. Gibson (Eds.), Virtual teams that work: Creating conditions for virtual team effectiveness (pp. 335-352). JosseyBass, San Francisco, CA.

Hackett, E. J. (2005). Essential tensions: Identity, control, and risk in research. Social Studies of Science, 35(5), 787-826. https://doi.org/10.1177/0306312705056045

Hampton, S. E., Strasser, C. A., Tewksbury, J. J., Gram, W. K., Budden, A. E., Batcheller, A. L., Duke, C. S., \& Porter, J. H. (2013). Big data and the future of ecology. Frontiers in Ecology and the Environment, 11(3), 156-162. https://doi.org/10.1890/120103

Healey, M. P., Vuori, T., \& Hodgkinson, G. P. (2015). When teams agree while disagreeing: Reflexion and reflection in shared cognition. Academy of Management Review, 40(3), 399-422. https://doi.org/10.5465/ amr.2013.0154

Hoffman, D. M., Blasi, B., Ćulum, B., Dragšić, Ž., Ewen, A., Horta, H., Nokkala, T., \& Rios-Aguilar, C. (2014). The methodological illumination of a blind spot: Information and communication technology and international research team dynamics in a higher education research program. Higher Education, 67(4), 473-495. https://doi.org/10.1007/s10734-013-9692-y 
Holdren, J. (2013). Memorandum for the heads of executive departments and agencies: Increasing access to the results of federally funded scientific research. United States. Office of Science and Technology Policy. Ipetition $\underline{\text { /require-free-access-over-internet-scientific-journal-articles-arising-taxpayer-funded }}$

Im, I., Hong, S., \& Kang, M. S. (2011). An international comparison of technology adoption: Testing the UTAUT model. Information \& Management, 48(1), 1-8. https://doi.org/10.1016/j.im.2010.09.001

Kim, D. J., Hebeler, J., Yoon, V., \& Davis, F. (2018). Exploring determinants of semantic web technology adoption from IT professionals' perspective: Industry competition, organization innovativeness, and data management capability. Computers in Human Behavior, 86, 18-33. https://doi.org/10.1016/j.chb.2018 $\underline{.04 .014}$

Kinzie, J., Magolda, P., Kezar, A., Kuh, G., Hinkle, S., \& Whitt, E. (2007). Methodological challenges in multi-investigator multi-institutional research in higher education. Higher Education, 54(3), 469-482. https://doi.org/10.1007/s10734-006-9007-7

Knoppers, B., Harris, J. R., Tassé, A., Budin-Ljøsne, I., Kaye, J., Deschênes, M., \& Zawati, M. H. (2011). Towards a data sharing Code of Conduct for international genomic research. Genome Medicine, 3(7), 46. https://doi.org/10.1186/gm262

Leahey, E. (2016). From sole investigator to team scientist: Trends in the practice and study of research collaboration. Annual Review of Sociology, 42(1), 81-100. https://doi.org/10.1146/annurev-soc-081715 $\underline{-074219}$

Lewis, M. (2010). Libraries and the management of research data. In S. McKnight (Ed.), Envisioning Future Academic Library Services (1st ed., pp. 145-168). Facet. https://doi.org/10.29085/9781856048750.011

Liggett, A. M., Glesne, C. E., Johnston, A. P., Hasazi, S. B., \& Schattman, R. A. (1994). Teaming in qualitative research: Lessons learned. International Journal of Qualitative Studies in Education, 7(1), 77-88. https://doi.org/10.1080/0951839940070106

Llebot, C., Rempel, H. G. (2020) Instruments to explore the adoption of good data management practices through a variation of the UTAUT model. (Version 1) [Dataset]. Oregon State University. https://doi.org $\underline{10.7267 / 5 \times 21 \operatorname{tn} 73 z}$

López-Yáńez, J., \& Altopiedi, M. (2015). Evolution and social dynamics of acknowledged research groups. Higher Education (00181560), 70(4), 629-647. https://doi.org/10.1007/s10734-014-9835-9

National Academy of Sciences (U.S.), \& National Academy of Engineering (U.S.) and Institute of Medicine (U.S.) Committee on Ensuring the Utility and Integrity of Research Data in a Digital Age. (2009). Ensuring Access to Research Data. In Ensuring the Integrity, Accessibility, and Stewardship of Research Data in the Digital Age. National Academies Press (US). https://www.ncbi.nlm.nih.gov/books/NBK215271/

National Science Foundation. (2019, May 20). Dear Colleague Letter: Effective Practices for Data (nsf19069) | NSF-National Science Foundation. https://www.nsf.gov/pubs/2019/nsf19069/nsf19069.jsp

Neylon, C. (2017). Compliance culture or culture change? The role of funders in improving data 
management and sharing practice amongst researchers. Research Ideas and Outcomes, 3, e21705. https://doi .org/10.3897/rio.3.e21705

Nosek, B. A., Alter, G., Banks, G. C., Borsboom, D., Bowman, S. D., Breckler, S. J., Buck, S., Chambers, C. D., Chin, G., Christensen, G., Contestabile, M., Dafoe, A., Eich, E., Freese, J., Glennerster, R., Goroff, D., Green, D. P., Hesse, B., Humphreys, M., ... Yarkoni, T. (2015). Promoting an open research culture. Science, 348(6242), 1422-1425. https://doi.org/10.1126/science.aab2374

Perkel, J. M. (2019). 11 ways to avert a data-storage disaster. Nature, 568(7750), 131-132. https://doi.org /10.1038/d41586-019-01040-w

Piwowar, H. A. (2011). Who shares? Who doesn't? Factors associated with openly archiving raw research data. PLoS ONE, 6(7), e18657. https://doi.org/10.1371/journal.pone.0018657

Rans, J., \& White, A. (2017). Using RISE, the research infrastructure self evaluation framework. Digital Curation Centre. http://www.dcc.ac.uk/resources/how-guides/RISE\#4

Rempel, H. G., \& Markland, M. (2018). Bridging the relationship gap: Using social network theories to inform library services for graduate students. In the Library with the Lead Pipe. 12018/bridging-the -relationship-gap/

Rempel, H. G., \& Robertshaw, M. B. (2017). Supporting the research practices of agricultural scientists at Oregon State University. Journal of Agricultural \& Food Information, 18(3-4), 276-292. https://doi.org/10 $\underline{.1080 / 10496505.2017 .1318073}$

Reznik-Zellen, R., Adamick, J., \& McGinty, S. (2012). Tiers of research data support services. Journal of EScience Librarianship, 27-35. https://doi.org/10.7191/jeslib.2012.1002

Salazar, M. R., \& Lant, T. K. (2018). Facilitating innovation in interdisciplinary teams: The role of leaders and integrative communication. Informing Science: The International Journal of an Emerging Transdiscipline, 21, 157-. Academic OneFile. https://doi.org/10.28945/4011

Stuart, D., Baynes, G., Hrynaszkiewicz, I., Allin, K., Penny, D., Lucraft, M., \& Astell, M. (2018). Whitepaper: Practical challenges for researchers in data sharing. https://doi.org/10.6084/m9.figshare.5975011 . $\mathrm{v1}$

Tenopir, C., Allard, S., Douglass, K., Aydinoglu, A. U., Wu, L., Read, E., Manoff, M., \& Frame, M. (2011). Data sharing by scientists: Practices and perceptions. PLOS ONE, 6(6), e21101. https://doi.org/10 .1371 /journal.pone.0021101

Tenopir, C., Allard, S., Frame, M., Birch, B., Baird, L., Sandusky, R., Langseth, M., Hughes, D., \& Lundeen, A. (2015). Research data services in academic libraries: Data intensive roles for the future? Journal of EScience Librarianship, 4(2), e1085. https://doi.org/10.7191/jeslib.2015.1085

Tenopir, C., Birch, B., \& Allard, S. (2012). Academic libraries and research data services: Current practices and plans for the future [ACRL white paper]. ACRL. http://www.ala.org/acrl/sites/ala.org.acrl/files/content /publications/whitepapers/Tenopir Birch Allard.pdf 
Tenopir, C., Dalton, E. D., Allard, S., Frame, M., Pjesivac, I., Birch, B., Pollock, D., \& Dorsett, K. (2015). Changes in data sharing and data reuse practices and perceptions among scientists worldwide. PLOS ONE, 10(8), e0134826. https://doi.org/10.1371/journal.pone.0134826

Tenopir, C., Sandusky, R. J., Allard, S., \& Birch, B. (2014). Research data management services in academic research libraries and perceptions of librarians. Library \& Information Science Research, 36(2), 84-90. https:// doi.org/10.1016/j.lisr.2013.11.003

Velden, T. (2013). Explaining field differences in openness and sharing in scientific communities. Proceedings of the 2013 Conference on Computer Supported Cooperative Work, 445. https://doi.org/10 $.1145 / 2441776.2441827$

Venkatesh, V., Morris, M. G., Davis, G. B., \& Davis, F. D. (2003). User acceptance of information technology: Toward a unified view. MIS Quarterly, 27(3), 425-478. https://doi.org/10.2307/30036540

Whitmire, A. L., Boock, M., \& Sutton, S. C. (2015). Variability in academic research data management practices: Implications for data services development from a faculty survey. https://doi.org/10.1108/PROG-02 $\underline{-2015-0017}$

Whyte, A. (2014, June). Final results from the DCC RDM 2014 survey. DCC Because Good Research Needs Good Data. http://www.dcc.ac.uk/blog/rdm-2014-survey

Wilkinson, M. D., Dumontier, M., Aalbersberg, Ij. J., Appleton, G., Axton, M., Baak, A., Blomberg, N., Boiten, J.-W., da Silva Santos, L. B., Bourne, P. E., Bouwman, J., Brookes, A. J., Clark, T., Crosas, M., Dillo, I., Dumon, O., Edmunds, S., Evelo, C. T., Finkers, R., ... Mons, B. (2016). The FAIR Guiding Principles for scientific data management and stewardship. Scientific Data, 3, 160018. https://doi.org/10 $\underline{.1038 / \text { sdata.2016.18 }}$

Wilson, S. R., Barley, W. C., Ruge-Jones, L., \& Poole, M. S. (2020). Tacking amid tensions: Using oscillation to enable creativity in diverse teams. The Journal of Applied Behavioral Science, 0021886320960245. https:// doi.org/10.1177/0021886320960245

Wuchty, S., Jones, B. F., \& Uzzi, B. (2007). The increasing dominance of teams in production of knowledge. Science, 316(5827), 1036-1039. https://doi.org/10.1126/science.1136099

Zuiderwijk, A., Janssen, M., \& Dwivedi, Y. K. (2015). Acceptance and use predictors of open data technologies: Drawing upon the unified theory of acceptance and use of technology. Government Information Quarterly, 32(4), 429-440. https://doi.org/10.1016/j.giq.2015.09.005 